RODRIGO DE SALLES OLIVEIRA MALTA BELDA

\title{
LIMITE DOS DISCURSOS DE ÓDIO E UMA CRÍTICA À VISÃO BRASILEIRA
}

Dissertação de Mestrado

Orientadora: Professora Associada Janaina Conceição Paschoal

UNIVERSIDADE DE SÃO PAULO

FACULDADE DE DIREITO

São Paulo

2017 


\section{RODRIGO DE SALLES OLIVEIRA MALTA BELDA}

\section{LIMITE DOS DISCURSOS DE ÓDIO E UMA CRÍTICA À VISÃO BRASILEIRA}

Dissertação apresentada à Banca Examinadora do Programa de PósGraduação em Direito, da Faculdade de Direito da Universidade de São Paulo, como exigência parcial para obtenção do título de Mestre em Direito, na área de concentração de Direito Penal, Medicina Forense e Criminologia, sob a orientação da Professora Associada Janaina Conceição Paschoal 
Autorizo a reprodução e divulgação total ou parcial deste trabalho, por qualquer meio convencional ou eletrônico, para fins de estudo e pesquisa, desde que citada a fonte.

Belda, Rodrigo de Salles Oliveira Malta

Direito Penal, Limite dos discursos de ódio e uma crítica à visão brasileira; orientadora Janaina Conceição Paschoal - 2017.

Dissertação (Mestrado em Direito) - Programa de Pós Graduação da Faculdade de Direito da Universidade de São Paulo, São Paulo, 2017.

Catalogação da Publicação

Serviço de Biblioteca e Documentação

Faculdade de Direito da Universidade de São Paulo

Belda, Rodrigo de Salles Oliveira Malta

.. Limite dos discursos de ódio e uma crítica à visão brasileira / Rodrigo de Salles Oliveira Malta Belda ; orientadora Janaina Conceição Paschoal -- São Paulo, 2017.

$195 \mathrm{f}$.

Dissertação (Mestrado - Programa de Pós-Graduação em Direito Penal, Medicina Forense e Criminologia) - Faculdade de Direito, Universidade de São Paulo, 2017.

1. Direito. 2. Direito Penal . 3. Liberdade de Expressão. 4. Discursos de ódio . I. Paschoal, Janaina Conceição, orient. II. Título. 
Nome: BELDA, Rodrigo de Salles Oliveira Malta

Título: Limite dos discursos de ódio e uma crítica à visão brasileira

Dissertação apresentada à Faculdade de Direito da Universidade de São Paulo como exigência parcial para obtenção do título de Mestre em Direito.

Aprovado em:

Banca Examinadora

Prof.Dr.

Instituição:

Julgamento:

Assinatura:

Prof.Dr.

Instituição:

Julgamento:

Assinatura:

Prof.Dr.

Instituição:

Julgamento:

Assinatura: 


\section{AGRADECIMENTOS}

A toda a minha família, especialmente meus pais e meu inseparável melhor amigo, meu irmão, e à maior luz que já passou na minha vida, a quem dedico estas lágrimas que caem enquanto escrevo estas palavras, Dona Anna;

À minha inspiração, razão da minha vida e do meu futuro, Ana Carolina; sem você o mundo é nada (desnecessário agradecer "sua" família, porque a eles vai a dedicatória ali de cima);

A todos os amigos da Facvldade, especialmente para XI em Campo, o grupo mais importante do qual já fiz parte, e que me trouxe histórias e alegrias incontáveis do primeiro ao último dia desta "breve" carreira;

A todos os amigos da vida, do Lourenço, Santa, Armadilha, e pra todos os outros que fazem bem ao mundo;

A todos os meus Professores, que merecem todo e qualquer mérito que venha deste trabalho. 


\section{RESUMO}

BELDA, Rodrigo de Salles Oliveira Malta Belda. Direito Penal, Limit of hate speech and criticism of the Brazilian view, 2017. Dissertação (Mestrado). Faculdade de Direito, Universidade de São Paulo, São Paulo, 2017.

Trata a presente dissertação de estudo acerca do entendimento doutrinário e jurisprudencial brasileiro dos discursos de ódio. O tema é estudado eminentemente a partir do julgamento do caso Ellwanger pelo Supremo Tribunal Federal. Para compreensão atualizada do tema, busca-se entender, inicialmente, o tipo penal formal que abrange os discursos de ódio (Artigo 20 da Lei $\mathrm{n}^{\circ}$ 7.716/89), e comparar o entendimento traçado pelo Supremo Tribunal Federal há mais de uma década com decisões paradigmáticas mais recentes que versaram igualmente sobre a liberdade de expressão (Caso da Lei de Imprensa e Caso dos Humoristas), sempre apresentando olhar crítico sobre o modo de julgamento dos casos, especialmente em razão da técnica interpretativa adotada. Apresenta-se, em seguida, crítica simultânea ao entendimento jurisprudencial e doutrinário dominante, explicando por quais motivos o Direito Penal e seus princípios não foram - mas deveriam ter sido - levados em consideração na fixação dos limites do exercício da liberdade de expressão por meio dos discursos de ódio. Apresenta-se, também, posição adotada neste estudo a respeito da fixação de outro limite para a regulação dos discursos de ódio, qual seja, as fight words, entendendo-o aplicável à realidade e ao arcabouço jurídico brasileiro. Por fim, registro o resultado de pesquisa jurisprudencial a respeito do tema, delimitando os critérios da pesquisa e trazendo notas interpretativas e comparativas dos julgados.

\section{PALAVRAS-CHAVE: DISCURSO DE ÓDIO - HATE SPEECH - LIMITE DA LIBERDADE DE EXPRESSÃO - CASO ELLWANGER - PESQUISA JURISPRUDENCIAL}




\begin{abstract}
BELDA, Rodrigo de Salles Oliveira Malta Belda. Criminal Law, the limit of hate speech and criminal practice, 2017. Dissertation (Master). Faculty of Law, University of São Paulo, São Paulo, 2017.

This dissertation deals with Brazilian doctrinal and jurisprudential understanding of hate speech. The subject is studied eminently from the judgment of the Ellwanger case by the Federal Supreme Court. For an up-to-date understanding of the topic, it is sought to understand, initially, the formal criminal type that encompasses hate speech (Article 20 of Law 7.716 / 89), and compare the understanding established by the Federal Supreme Court over a decade ago with decisions (Law Press Case and Case of Humorists), always presenting a critical view on the way of judgment of the cases, especially due to the interpretive technique adopted. This is followed by a simultaneous criticism of the dominant jurisprudential and doctrinal understanding, explaining why the Criminal Law and its principles were not - but should have been - taken into account when setting the limits of the exercise of freedom of expression through Speeches of hatred. It is also presented the position adopted in this study regarding the establishment of another limit for the regulation of hate speech, that is, the fight words, understanding it applicable to the reality and the Brazilian legal framework. Finally, I register the result of a jurisprudential research on the subject, delimiting the criteria of the research and bringing interpretative and comparative notes of the judged ones.
\end{abstract}

KEYWORDS: HATE SPEECH - HATE SPEECH - LIMITATION OF FREEDOM OF EXPRESSION - ELLWANGER CASE - JURISPRUDENTIAL RESEARCH 


\section{SUMÁRIO}

1. Introdução

2. Os discursos de ódio

2.1 Tipo penal, Definição e Terminologia

2.2 Breve panorama

3. Panorama da legislação penal sobre racismo e preconceito no Brasil

4. A visão do Supremo Tribunal Federal sobre os discursos de ódio (Caso Ellwanger) e análise de casos mais recentes da Suprema Corte sobre a liberdade de expressão - Caso da Lei de Imprensa e Caso dos Humoristas

4.1. Caso da Lei de Imprensa

4.1.1 Voto do Ministro Carlos Ayres Britto

4.1.2 Voto do Ministro Menezes Direito

4.1.3 Voto da Ministra Carmen Lúcia

4.1.4 Voto do Ministro Ricardo Lewandowski

4.1.5 Voto do Ministro Joaquim Barbosa

4.1.6 Voto do Ministro Cezar Peluso

4.1.7 Aparte da Ministra Ellen Gracie

4.1.8 Voto do Ministro Marco Aurélio

4.1.9 Voto do Ministro Celso de Mello

4.1.10 Voto do Ministro Gilmar Mendes

4.1.11 Notas conclusivas

4.2. Caso dos humoristas

4.2.1 Voto do Ministro Ayres Britto

4.2.2 Voto do Ministro Dias Toffoli

4.2.3 Notas conclusivas

4.3. Caso Ellwanger

4.3.1 Voto do Ministro Moreira Alves

4.3.2 Voto do Ministro Maurício Corrêa

4.3.3 Voto do Ministro Celso de Mello

4.3.4 Voto do Ministro Gilmar Mendes 
4.3.5 Voto do Ministro Carlos Veloso

4.3.6 Voto do Ministro Nelson Jobim

4.3.7 Voto da Ministra Ellen Gracie

4.3.8 Voto do Ministro Cezar Peluso

4.3.9 Voto do Ministro Carlos Ayres Britto

4.3.10 Voto do Ministro Marco Aurélio

4.3.11 Voto do Ministro Sepúlveda Pertence

4.3.12 Notas conclusivas

5. Política criminal e a adoção do direito penal no combate ao racismo e ao preconceito

5.1. Dos pressupostos para utilização da Lei penal

6. O limite dos discursos de ódio

7. Pesquisa jurisprudencial

7.1 Superior Tribunal de Justiça

7.2 Tribunal de Justiça do Estado de São Paulo

7.3 Tribunal de Justiça do Estado da Bahia

7.4 Tribunal de Justiça do Estado do Rio de Janeiro

7.5 Conclusões gerais a respeito da pesquisa jurisprudencial

8. Conclusão

BIBLIOGRAFIA 


\section{INTRODUÇÃO}

O presente trabalho busca examinar a tutela penal sobre os discursos racistas e preconceituosos, conhecidos como "discursos de ódio", que consistem em manifestações de idéias que incitam a discriminação racial, social ou religiosa em relação a determinados grupos, na maioria das vezes a minoria, ${ }^{1}$ seja por meio de filmes, livros, cartazes, propaganda ou outro tipo de veiculação de ideias. ${ }^{2}$

Inicialmente, analisa-se a legislação infraconstitucional (em especial o caput do artigo 20 da Lei $n^{\circ} 7.716 / 1989$ - que teve alterações dadas pelas Leis 9.459/1997 e 8.081/1990) que, segundo julgamento paradigmático do Supremo Tribunal Federal (Caso Ellwanger), é a peça normativa responsável pela possibilidade de incriminação dos discursos de ódio. Nesta parte do trabalho indica-se significativa crítica ao tipo penal formulado pelo Legislador nacional, e define-se o que são os discursos de ódio.

Em seguida, tratou-se de apresentar as principais correntes interpretativas a respeito do limite do exercício da liberdade de expressão no que diz respeito aos discursos de ódio (norte-americana e europeia/brasileira, em síntese), expondo também o histórico da legislação brasileira sobre a matéria do racismo e do preconceito.

Apresenta-se, também, pesquisa jurisprudencial, dividida em duas partes.

A primeira parte diz respeito aos precedentes do Supremo Tribunal Federal. Como não poderia deixar de ser, revisitou-se o conhecido caso Ellwanger (Habeas Corpus $n^{\circ} 82.424 / \mathrm{RS}$ ), em que o Supremo Tribunal Federal, por maioria, estendeu o combate ao racismo também à vedação do discurso do ódio, assegurando, em tese, o princípio da isonomia ${ }^{3}$ - citando diversos estudos que foram feitos a seu respeito. ${ }^{4}$

Ainda nesta primeira parte da pesquisa jurisprudencial, por contemplarem

\footnotetext{
${ }^{1}$ MEYER-PFLUG, S.A, Liberdade de expressão e discurso de ódio, Ed. Revista dos Tribunais, São Paulo, 2009, p. 97.

2 BAKER, M.G, Reflexos sobre o "hate speech" (discurso de ódio), in Boletim IBCCRIM, JUL/2012, ano $20, \mathrm{n}^{\circ} 236$, p. 12 .

${ }^{3}$ MEYER-PFLUG, S.A, Avanços e cuidados na proteção dos direitos, in Princípios Constitucionais Relevantes - A constituição Interpretada pelo Conselho Superior da Fecomércio, Ives Gandra Martins (coord), 2011, Ed. Magister, Porto Alegre, 2012, p. 129.

${ }^{4}$ A citar, por exemplo: DA SILVA, R.L, NICHEL, A, MARTINS, A.C.L, BORCHARDT, C.K, Discursos de ódio em redes sociais: jurisprudência brasileira, in Revista Direito GV, JUL/DEZ 2011, v. 7, $\mathrm{n}^{\mathrm{o}}$ 2, p. 445-468; MARQUES, A.R.M, MUNIZ, A.B, BRANDÃO, M. S, A liberdade de expressão e suas ameaças: reflexões a partir do caso Ellwanger (HC 82.424), in Casos Constitucionais em destaque: princípios fundamentais, coord. PARDO, D.W.A, Série Monografias do CEJ, Brasília, maio/ago. 2013.
} 
igualmente os limites do exercício do direito à livre expressão, e por terem sido casos julgados mais recentemente pela Corte Superior, foram analisados também os votos elaborados na ADPF 130 (Lei de Imprensa) e na ADI 4451 (Caso dos Humoristas).

A análise destes dois casos se mostrou especialmente importante, pois já há posição que defende a aparição de contradição entre a atividade interpretativa desenvolvida pelo Tribunal nestas ocasiões e a fundamentação exposta pelo Supremo Tribunal Federal no caso Ellwanger, já que, apesar de terem discutido o humorismo na atividade comunicativa durante o período eleitoral e a recepção da Lei de Imprensa como um todo, e não os discursos de ódio, se o "modelo mental" da ADPF 130 e da ADI 4451 prevalecer (primazia da liberdade de expressão e submissão aos efeitos cíveis por seus excessos) em casos de discurso do ódio, ter-se-ia uma nítida contradição com as conclusões antes adotadas. ${ }^{5}$

Desde já, deve-se dizer que ao final de cada um destes três casos estudados são apresentadas notas conclusivas, em que se pode ter uma visão crítica sobre os julgamentos da Suprema Corte.

Os capítulos que seguem constituem a principal parte teórica desta dissertação, pois então se apresenta a visão autoral sobre a colisão da liberdade de expressão com outros bens jurídicos constitucionalmente tutelados, porém sob o ponto de vista do Direito Penal, a partir do que é possível perceber que o entendimento adotado no presente pelo Supremo Tribunal Federal, que criminalizou os discursos de ódio, seguiu uma lógica punitiva que não respeita a máxima efetividade do direito fundamental sobre o qual se está a discutir, e, principalmente, que a posição majoritária da doutrina e jurisprudência brasileira não aplica corretamente os princípios que balizam o direito penal mínimo e os pressupostos de criação da lei penal. Ao final desta parte teórica, é apresentada posição diversa a respeito de qual deveria ser o limite da liberdade de expressão quando se fala em discursos de ódio (fight words).

Posteriormente, apresenta-se a segunda parte da pesquisa jurisprudencial desenvolvida neste trabalho.

Tendo em vista a necessidade de aproximar os estudos doutrinários e teóricos da prática atual de nossos Tribunais, elaborou-se pesquisa qualitativa dos casos de preconceito previstos no artigo 20 da Lei $\mathrm{n}^{\circ} 7.716 / 89$, especialmente manifestados em

\footnotetext{
${ }^{5}$ RODRIGUES JUNIOR, O.A, Justiça do Canadá amplia conceito de "discurso do ódio", disponível em http://www.conjur.com.br/2013-mai-01/direito-comparado-justica-canada-amplia-conceito-discurso-odio, acessado em 13/10/2013.
} 
sua forma verbal, apresentados ao Superior Tribunal de Justiça e a Tribunais de três Estados brasileiros (São Paulo, Rio de Janeiro e Bahia).

Assim como foi feito com os precedentes do Supremo Tribunal Federal, ao final da indicação caso a caso nos Tribunais, apresentam-se conclusões a seu respeito, apontando, entre outras coisas, que a conduta preconceituosa que hoje é criminalizada pela soma de um tipo penal extremamente aberto com uma interpretação questionável do Supremo Tribunal Federal, poderia encontrar solução jurídica diversa do Direito Penal - como, na verdade, deveria, pelo que se verá na parte teórica desta obra.

Cumpre deixar registrado que o estudo do tema muitas vezes debruça-se de forma mais apurada sobre o estudo das manifestações odiosas de cunho racial, o que não significa que o tema dos discursos de ódio se restrinja a análise de veiculação de idéias desta natureza.

Ocorre que a expansão da criminalização dos discursos de ódio, no Brasil, guarda relação direta com a criminalização do racismo decorrente de raça ou cor, prevista na Constituição Federal em decorrência da forte e organizada militância do movimento negro, e interpretada no paradigmático Caso Ellwanger, que tratou exaustivamente do conceito de raça.

Assim, por mais que a preocupação com o racismo possa parecer equívoco técnico ou de delimitação do tema a ser tratado, não é possível ainda analisar profundamente e didaticamente o tema sem fazer referência às questões que tem origem no preconceito de raça, especialmente porque foi em julgamento a respeito do preconceito decorrente de raça que o Supremo Tribunal Federal expandiu o alcance do crime de racismo para a veiculação de idéias odiosas. 


\section{CONCLUSÃO}

Viu-se, no presente trabalho, que há consideráveis críticas à criminalização dos discursos de ódio no Brasil.

O primeiro motivo é a pobre técnica legislativa adotada no país, que, por meio do caput do artigo 20 da Lei $\mathrm{n}^{\circ} 7.716 / 1989$, previu de forma inaceitavelmente aberta inúmeras condutas possivelmente reprováveis, quando fixou como núcleo do tipo a palavra "praticar" - verbo este que aceita o enquadramento de incontáveis condutas humanas.

O segundo, como visto principalmente na parte teórica do trabalho, diz respeito à própria formulação de um tipo penal inclinado a uma satisfação mais política do que jurídica, sem respeito aos pressupostos científicos que antecipam a necessidade de criação de mecanismos de repressão criminal - algo que, de forma prática, é confirmado pela analise jurisprudencial que se faria ao final, e especialmente diante de alternativas como aquela proposta pela Defensoria Pública do Estado de São Paulo.

Sem prejuízo, constatou-se que a atividade interpretativa levada a cabo pelo Supremo Tribunal Federal quanto à liberdade de expressão, especialmente no caso Ellwanger, vem sendo feita de maneira inadequada, seja porque não se ponderou com especial consideração, em nenhum momento, a natureza penal da causa que estava se pondo em debate (criminalização do racismo por meio de diversas formas da liberdade de expressão), seja porque o método interpretativo constantemente utilizado não se apresenta da melhor maneira, ou, como dito pelo próprio Ministro Dias Toffoli em mais de uma ocasião, de maneira científica e "não sofista".

O Judiciário, em atividade simbólica, como alertou o Ministro Marco Aurélio no caso Ellwanger, estendeu indevidamente, e também ao arrepio dos princípios do direito penal mínimo, o conteúdo e alcance do tipo penal de racismo, para abarcar situações abstratas não desejadas pelo Legislador. Vale dizer, se a Lei não deveria prever e não previu expressamente a necessidade de repressão à mera manifestação de ódio, a interpretação judicial não poderia fazê-lo.

Teve-se também oportunidade de percorrer decisões não apenas da Corte Superior, mas também, e principalmente, de Tribunais Estaduais, o que veio a demonstrar que a norma penal, concretamente, vem sendo aplicada com dificuldade e sem pacificação pelas instâncias inferiores. Não obstante, pode-se concluir, com base no estudo dos casos, que a maioria dos problemas que o tipo penal criado pelo legislador 
busca resolver ou reprimir, poderia ser resolvido recorrendo-se a outros tipos de mecanismos estatais ou mesmo repressores, especialmente porque os destinatários da reprimenda penal acabam por ser pessoas contra quem, em tese, não se destinaria a vontade do legislador - vale dizer, pessoas que não ofendem de forma decisiva e ameaçadora a dignidade dos grupos vulneráveis.

Por fim, e em suma, restou delineada integralmente a crítica quanto à escolha da política criminal levada a efeito no país, em razão de sua lógica exclusivamente punitiva, que veio a ser consagrada com o apoio em legislação penal de duvidosa técnica, e interpretação do Supremo Tribunal Federal totalmente dissociada dos princípios específicos do Direito Penal. 


\section{BIBLIOGRAFIA E REFERÊNCIAS BIBLIOGRÁFICAS}

ALEXY, Robert, Teoria dos Direitos Fundamentais, Tradução de Virgílio Afonso da Silva, $2^{\mathrm{a}}$ ed., Malheiros, São Paulo, 2014.

ALMEIDA, Fernanda Dias Menezes de. A proteção constitucional e legal da liberdade de expressão do pensamento no Brasil. Revista da Procuradoria Geral do Estado de São Paulo. n.39. p.167-77. jun. 1993.

AUGUSTO, Silmara Maria, MARTA, Tais Nader. Mandado de criminalização do racismo, Revista Direito e Humanidades, ano X, n. 16, p. 161-181, 2009.

ARAGÃO, Eugênio José Guilherme. Racismo é crime internacional, in Boletim dos Procuradores da República, nº 46, 2002.

BAKER, Milena Gordon. Reflexões sobre o "hate speech" (discurso de ódio), in Boletim IBCCRIM, JUL/2012, ano 20, nº 236.

BALKIN, Jack M. How rights change: freedom of speech in the digital era. The Sydney Law Review. Sydney. v.26. n.1. p.5-16. mar. 2004.

BAPTISTA DE ABREU, Irahy, O racismo e a jurisprudência do Egrégio Tribunal de Justiça do Estado de São Paulo, in 10 anos da Constituição e a Justiça Penal, Meio Ambiente, Drogas, Globalização, o caso Pataxó, coord. PENTEADO, Jaques de Camargo, São Paulo, RT, 1999.

BARROSO, Luis Roberto; MARTEL, Letícia de Campos Velho, Dignidade e autonomia individual no final da vida, disponível em http://www.conjur.com.br/2012jul-11/morte-ela-dignidade-autonomia-individual-final-vida.

BARROSO, Luís Roberto. Colisão entre liberdade de expressão e direitos da personalidade: critérios de ponderação: interpretação constitucionalmente adequada do código civil e da lei de imprensa. Revista de Direito Administrativo. Rio de Janeiro. n.235. p.1-36. 2004. 
BASTOS, Celso Ribeiro. Os limites a liberdade de expressão na Constituição da Republica. Revista Forense. Rio de Janeiro. v.96. n.349. p.43-51. jan./mar. 2000.

BECHARA, Ana Elisa Liberatore S. Democracia, liberdade de expressão e dissenso: Marcha da Maconha e limites constitucionais à interpretação do art. 287 do CP. Revista Brasileira de Ciências Criminais. São Paulo. v.19. n.91. p.489-530. jul./ago. 2011.

BELANDRIA, Margarita; GANZÀLEZ REINOZA, Javier. La libertad de expresión: de la doctrina a la ley. Dikaiosyne. Mérida. v.8. n.14. p.73-93. jun. 2005.

BELTRÁN C., Mauricio. Dos caminos diferentes para arribar al mismo lugar. La libertad de expresión en Canadá y Estados Unidos. Revista Sócio Jurídicos. Bogotá. v.7. n.1. p.93-116. ene./jun. 2005.

BIANCHINI, Alice. Pressupostos materiais mínimos da tutela penal. São Paulo: RT, 2002.

BICKET, Douglas. Drifting apart together: diverging comceptions of free expression in the North American Judicial Tradition. Communications and the Law. Westport. v.20. n.4. p.1-38. dez. 1998.

BITENCOURT, Cezar Roberto, Tratado de Direito Penal: parte geral, Saraiva, $20^{\mathrm{a}}$ ed.,São Paulo, 2014.

BITENCOURT, Cezar Roberto, Tratado de Direito Penal - parte especial, v. 2, Saraiva, 2004.

BLAZQUEZ-RUIZ, Francisco Javier, Introducción: genealogia, dinâmica y propuestas éticas frente AL racismo y xenofobia, in 10 palabras clave sobre El racismo y xenofobia. Estella: Verbo Divino, 1996, apud MEYER-PFLUG, S.A, Liberdade de expressão e discurso de ódio, Ed. Revista dos Tribunais, São Paulo, 2009. 
BOBBIO, Norberto, Elogio da serenidade: e outros escritos morais, trad. Marco Aurélio Nogueira, 2ª Edição, Ed. UNESP, São Paulo, 2011.

BOBBIO, Norberto, Teoria do ordenamento jurídico, trad. Ari Marcelo Solon, São Paulo, Ed. EDIPRO, 2011.

BORGARELLO, Esther S; JUÁREZ CENTENO, Carlos. Evolución de la regulación constitucional de la libertad de expresión análisis: comparativo entre la nación y la provincia de Córdoba. Anuário. Centro de Investigaciones Jurídicas y Sociales Facultad de Derecho y Ciências Sociales Universidad Nacional de Cordoba. Cordoba. v.5. p.309-24. 1999-2000.

BOTTINI, Pierpaolo Cruz; SHECAIRA, Sérgio Salomão; BERCOVICI, Gilberto, Lembrar o holocausto serve de aviso às futuras gerações, originalmente publicado na edição de 22/01/2013 do jornal Folha de São Paulo, disponível em http://www.conjur.com.br/2013-jan-22/lembrar-holocausto-serve-aviso-futurasgeracoes.

BOTTINI, P. C, É legítimo o projeto de lei que criminaliza o preconceito, disponível em http://www.conjur.com.br/2012-nov-27/direito-defesa-legitimo-projeto-criminalizarpreconceito.

BOTTINI, Pierpaolo Cruz, Negação do holocausto judeu é perigoso e preocupante, disponível em http://www.conjur.com.br/2012-dez-14/direito-defesa-negacao-massacrejudeu-perigoso-preocupante.

BOYD, Elizabeth A. et al. "Motivated by hatred or prejudice": categorization of hate-motivated crimes in two polices divisions. Law and Society Review. Denver. v.30. n.4. p.819-50. 1996.

BRUGGER, Winfried. Proibição ou proteção do discurso do ódio? algumas observações sobre o direito alemão e o americano. Direito Público. Porto Alegre, ano 4 n.15, p.117-136, jan/mar.2007. 
CALAZANS, Paulo Murillo, A liberdade de expressão como expressão da liberdade, in Temas de Constitucionalismo e Democracia, org. VIEIRA, José Ribas, Rio de Janeiro, Renovar, 2003.

CALEARI, Antonio, Malleus Holoficarum - o estatuto jurídico-penal da revisão histórica na forma do Jus Puniendi versus Animus Revidere, Editora Chiado, 2012.

CAPEZ, Fernando. Curso de Direito Penal - parte especial, v. 2, Saraiva, 2003.

CENTENO, Victor Barreto, Crimes de ódio como crimes politicamente motivados: uma análise conceitual do instituto, Porto Alegre, Faculdade de Direito da Universidade Federal do Rio Grande do Sul, 2014 [dissertação de conclusão de curso].

CANOTILHO, José Joaquim Gomes, Direito Constitucional, $6^{\mathrm{a}}$ ed, Coimbra, Almedina, 1993.

CARVALHO, Lucas Borges de. Justiça e liberdade de expressão: uma releitura do caso Ellwanger. Revista Brasileira de Estudos Constitucionais - RBEC, Belo Horizonte, ano 3, n. 10, abr./jun. 2009.

CICONELLO, Alexandre, O desafio de eliminar o racismo no Brasil: a nova institucionalidade no combate à desigualdade social, disponível em http://www.ceap.br/material/MAT24052014223326.pdf.

CRESPO, Cristina, Libertad de Expresión : Garantía de la Democracia, Seminário Libertad de Expresión (2011: Santiago, Chile), Vozes, 2011.

CRIADO DE DIEGO, Marcos; CABO DE LA VEGA, Antonio de. Actualidad constitucional en EEUU (2006/2007). La Constitución fuera de la Constitución. Teoria y Realidad Constitucional. Madrid. n.22. p.425-51. jul./dic. 2008.

DA SILVA, Eliezer Gomes, SFOGGIA, Ivonei. O crime de racismo na legislação penal brasileira: passado, presente e futuro. Revista Igualdade. Curitiba. v.5. n.14. p.11-29. jan/mar. 1997. 
DA SILVA, R.L, NICHEL, A, MARTINS, A.C.L, BORCHARDT, C.K, Discursos de ódio em redes sociais: jurisprudência brasileira, in Revista Direito GV, JUL/DEZ 2011, v. 7, nº 2, p. 445-468. Disponível em http://www.scielo.br/scielo.php?pid=S1808$\underline{24322011000200004 \& \text { script=sci_arttext }}$

DÍAZ ALDRET, Octavio. Conjeturas acerca de la limitación a la libertad de expresión, por respeto a los símbolos patrios caso deI poeta maldito. Cuestiones Constitucionales: revista mexicana de derecho constitucional. Mexico. n.16. p.369-403. ene./jun. 2007.

DOUGLAS-SCOTT, Sionaidh. The Hatefulness of Protected Speech: A Comparison of the American and European Approaches. William \& Mary Bill of Rights Journal 305 (1999). Disponível em: http://scholarship.law.wm.edu/wmborj/vol7/iss2/2. Acesso em: 12.10.2012.

DUNKUN, Betty L. Where to draw the line: handling religious harassment issues in the wake of the failed EEOC guidelines. Notre Dame Law Review. Notre Dame. v.71. n.5. p.953-89. 1996.

EMMERICH, Natalia Nardelli, PINTO DA COSTA, Simone. O Direito à liberdade de expressão e o discurso de ódio: da dissolução do paradigma liberal quanto ao direito de liberdade e o tratamento jurídico do hate speech. Revista Brasileiro de Direitos e Garantias Fundamentais, v. 1, n²2, p. 35-54, jul/dez 2015.

GANDRA DA SILVA MARTINS, Ives, Liberdade de expressão - inteligência dos Incisos IV, VI, VII e IX do Artigo $5^{\circ}$ da Constituição Federal - A correta Exegese de Repúdio ao "Discurso do Ódio" - Parecer, in Revista IOB de Direto Penal e Processual Penal, Ano X, nº 55, Abr/Mai 2009.

GARCIA, Guiomari Garson Dacosta. Estado democrático de direito e liberdade de expressão e informação. Revista de Direito Constitucional e Internacional. São Paulo. v.11. n.42. p.258-98. jan./mar. 2003. 
GONZÁLEZ MORALES, Felipe. Censura judicial y libertad de expresión: sistema interamericano $\mathbf{y}$ derecho chileno. Revista IIDH: Instituto Interamericano de Derechos Humanos. San José. v.43. n.1. p.239-80. ene./jun. 2006.

GRECO, Rogério. Curso de Direito Penal, parte especial, v. II, ed. Impetus, 2006.

GREENE, Dwight. Hate crimes. University of Miami Law Review. Miami. v.48. n.4. p.905-11. mar. 1994.

GRIN, Monica, MAIO, Marcos Chor, O antirracismo da ordem no pensamento de Afonso Arinos de Melo Franco, Topoi, Rio de Janeiro, v. 14, n. 26, p. 33-45, Junho/2013, disponível em http://www.scielo.br/pdf/topoi/v14n26/1518-3319-topoi-1426-00033.pdf.

GROSSMAN, Claudio. La libertad de expresión en el sistema interamericano de protección de los derechos humanos. Revista IIDH: Instituto Interamericano de Direitos Humanos. San José. v.46. ed. esp. p.159-93. jul./dic. 2007.

GUEDES, Clarissa Diniz. Presunção de inocência, liberdade de expressão e direito à informação: reflexões à luz da jurisprudência do Tribunal Europeu de Direitos do Homem e da Corte Americana de Direitos Humanos. Revista Forense. Rio de Janeiro. v.106. n.411. p.3-23. set/out. 2010.

GUEDES, Néviton, Liberdade e tolerância para as ideias que odiamos, disponível em http://www.conjur.com.br/2013-fev-25/constituicao-poder-liberdade-toleranciaideias-odiamos.

GUEDES, Néviton, Prevalência da liberdade religiosa e o direito à vida, disponível em http://www.conjur.com.br/2013-fev-18/constituicao-poder-prevalencia-liberdadereligiosa-direito-vida2.

GUIMARÃES, Antônio Sérgio Alfredo, Racismo e Anti-Racismo no Brasil, $2^{\mathrm{a}}$ ed., Editora 34, São Paulo, 2005. 
HARE, Ivan. Legislating against hate - The legal response to bias crimes. Oxford Journal of Legal Studies. Oxford. v.17. n.3. p.415-39. 1997.

HASIAN JUNIOR, Marouf A. Canadian civil liberties, holocaust denial, an the Zundel trials. Communications and the Law. Westport. v.21. n.3. p.43-56. sept. 1999.

HONÓRIO, Cláudia; KROL, Heloísa. Jurisdição constitucional, democracia e liberdade de expressão: análise do caso Ellwanger. A \& C: revista de direito administrativo e constitucional. Belo Horizonte. v.8. n.32. p.77-92. abr./jun. 2008

JARILLO GOMEZ, Juan Luis. Donde se encuentran los limites de los derechos fundamentales en relacion con la libertad de expresion. Revista de la Facultad de Derecho de la Universidad Complutense. Madrid. n.88. p.173-80. 1997.

KEANE, David. Attacking Hate Speech under Article 17 of the European Convention on Human Rights. Netherlands Quarterly of Human Right. Cambridge. v.25. n.4. p.641-64. Dec. 2007.

KENTRIDGE, Sydney. Freedom of speech: is it the primary right? International and Comparative Law Quarterly. London. v.45. n.2. p.253-70. apr. 1996.

KRSTICEVIC, Viviana. How inter-american human rights litigation brings free speech to the Americas. Southwestern Journal of Law and Trade in the Americas. Los Angeles. v.4. n.2. p.209-26. 1997.

LAFER, C, A internacionalização dos direitos humanos: o desafio do direito a ter

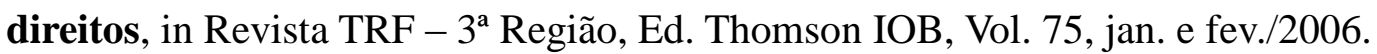

LAFER, Celso, $\mathbf{O}$ caso Ellwanger: anti-semitismo como crime da prática de racismo, in Revista de Informação Legislativa, Org. FONTOURA, Jorge, $\mathrm{n}^{\circ}$ 162, ano 41, abril/junho 2004.

LAWRENCE, Frederick M. Resolving the hate crimes/hate speech paradox: punishing bias crimes and protecting racist speech. Notre Dame Law Review. Notre 
Dame. v.68. n.4. p.673-722. 1993.

LEEPER, Roy. The Ku Klux Klan, public highways, and the public forum. Communications and the Law. Westport. v.22. n.4. p.39-59. dec. 2000.

LIMA, Larissa, Criminalizar discurso do ódio não fere a Constituição, disponível em http://www.conjur.com.br/2013-mar-07/larissa-lima-criminalizar-discurso-odio-naofere-liberdade-expressao.

LÓPEZ SALAS, Rafaela. El caso Sergio Witz: un conflicto de derechos? Cuestiones Constitucionales: revista mexicana de derecho constitucional. Mexico. n.16. p.435-49. ene./jun. 2007.

MACHADO, Maria Costa Neves, Liberdade de Expressão e restrições de conteúdo: Análise do Caso Ellwanger em diálogo com o pensamento de Celso Lafer, in Revista dos Tribunais, v. 931, maio/2013.

MACHADO, Marta Rodriguez de Assis. A legislação anti-racismo no Brasil e sua aplicação: um caso de insensibilidade do Judiciário. Revista Brasileira de Ciências Criminais. São Paulo. v.17. n.76. p.79-105. jan/fev. 2009.

MACHADO, Marta Rodriguez de Assis, SANTOS, Natália Neris da Silva, FERREIRA, Carolina Cutrupi. Legislação antirracista punitiva no Brasil: uma aproximação à aplicação do Direito pelos Tribunais de Justiça brasileiros . Revista de estudos empíricos em direito. São Paulo. v.2. n.1. p.60-92. jan 2015.

MAGGIE, Yvonne, Anti-Racismo contra leis raciais, disponível em http://www.institutomillenium.org.br/wp-content/uploads/2011/06/anti_racismo-contraleis-raciais.pdf.

MARCHERI, Pedro Lima, O Nazismo, Neonazismo e outras espécies de discriminação no sistema penal brasileiro, Marília, Fundação de Ensino Eurípides Soares da Rocha, 2014 [dissertação de Mestrado]. 
MARQUES, Amanda Ravena Martins, MUNIZ, Arnaldo Brasil, BRANDÃO, Maureen da Silva, A liberdade de expressão e suas ameaças: reflexões a partir do caso Ellwanger (HC 82.424), in Casos Constitucionais em destaque: princípios fundamentais, coord. PARDO, D.W.A, Série Monografias do CEJ, Brasília, maio/ago. 2013.

MARSHALL, Margaret. Dangerous talk, dangerous silence: free speech, judicial independence, and rule of law. The Sydney Law Review. Sydney. v.24. n.4. p.97-124. dec. 2002.

MARTINS, Leonardo. Sigfried Ellwanger: liberdade de expressão e crime de racismo: parecer 25 sobre o caso decidido pelo STF no HC 82.424/RS. Revista Brasileira de Estudos Constitucionais RBEC, Belo Horizonte, ano 1, n. 4, p. 179-209, out./dez. 2007.

MEIRA, Miguel Salgueiro. Limites à liberdade de expressão nos discursos de incitamento ao ódio. $\quad$ Disponível em http://www.verbojuridico.net/doutrina/2011/miguelmeira_limitesliberdadeexpressao.pdf

MENDES, Gilmar Ferreira. Colisão de direitos fundamentais:liberdade de expressão e de comunicação e direito a honra e a imagem. Revista de Informação Legislativa. Brasília. v.31. n.122. p.297-301. abr./jun. 1994.

MEYER, Nancy J. Free speech for college students: how much is Enough? Communications and the Law. Westport. v.13. n.1. p.69-97. mar. 1991.

MEYER-PFLUG, Samantha Ribeiro. Avanços e cuidados na proteção dos direitos, in Princípios Constitucionais Relevants - A constituição Interpretada pelo Conselho Superior da Fecomércio, Ives Gandra Martins (coord), 2011, Ed. Magister, Porto Alegre, 2012.

MEYER-PFLUG, Samantha Ribeiro. Liberdade de expressão e discurso de ódio, Ed. Revista dos Tribunais, São Paulo, 2009. 
MOREIRA, Alexandre Magno Fernandes. Crítica à incriminação do racismo. Revista Ciência Jurídica. Belo Horizonte. v.135,. n.21. p.285-310. mai/jun. 2007.

MURRAY, Daragh. Freedom of expression, counter-terrorism and the internet in light of the UK Terrorist Act 2006 and the jurisprudence of the European Court of Human Rights. Netherlands Quarterly of Human Rights. Cambridge. v.27. n.3. p.33160. Sept. 2009.

NEUTRAL rules of general applicability: incidental burdens on religion, speech, and property. Harvard Law Review. Cambridge. v.115. n.6. p.1713-36. apr. 2002.

NIEUWENHUIS, Aernout. Freedom of speech: USA vs Germany and Europe. Netherlands Quarterly of Human Rights. Cambridge. v.18. n.2. p.195-214. jun. 2000.

NUCCI, Guilherme de Souza, Código Penal Comentado, 7ª ed., RT, São Paulo, 2007.

NUCCI, Guilherme de Souza, Código Penal Comentado, RT, 2006.

NUCCI, Guilherme de Souza, Leis Penais e Processuais Penais Comentadas, $4^{\mathrm{a}}$ ed., RT, São Paulo, 2009.

OLIVEIRA JUNIOR, Juarez Monteiro de, Discurso do ódio e limitações não paternalistas da tolerância no Estado Democrático de Direito: uma crítica à decisão do Supremo Tribunal Federal no caso Ellwanger (HC n. 82424-2 RS), Belo Horizonte, Pontifícia Universidade Católica de Minas Gerais, 2008 [dissertação de Mestrado].

OMMATI, José Emílio Medauar, A constituição formal e rígida, a tensão constitutiva ao direito moderno entre facticidade e validade e a tipificação do crime de racismo na Constituição de 1988, in Revista de Direito Constitucional e Internacional, RT, $\mathrm{n}^{\text {o }}$ 55, Ano 14, abril-junho/2006.

ORENTLICHER, Diane F. Criminalizing hate speech in the crucible of trial: 
prosecutor v. nahimana. American University International Law Review. Washington D.C. v.21. n.4. p.557-96. 2006.

OZORIO DE MELO, João, EUA discutem onde acaba a liberdade de expressão e começa um delito, disponível em http://www.conjur.com.br/2013-out-09/justica-euadiscute-onde-acaba-liberdade-expressao-comeca-delito.

PASCHOAL, Janaina Conceição, Constituição, criminalização, e Direito Penal Mínimo, RT, São Paulo, 2003.

PASCHOAL, Janaína Conceição, República esquizofrênica, artigo publicado no jornal Folha de S. Paulo, em 09/10/2013.

PEREIRA, Robson, Livro mostra falta de diálogo entre juristas e jornalistas, disponível em http://www.conjur.com.br/2013-abr-15/estante-legal-livro-mostra-faltadialogo-entre-juristas-jornalistas.

PHILLIPS, Scott; GRATTET, Ryken. Judicial rhetoric, meaning-making, and the institutionalization of hate crime law. Law and Society Review. Denver. v.34. n.3. p.567-606. 2000.

POTIGUAR, Alex Lobato. Discurso de ódio no Estado Democrático de Direito: o uso da liberdade de expressão como forma de violência. Brasília: Universidade de Brasília, 2015 [dissertação de Doutorado].

POTIGUAR, Alex Lobato. Igualdade e liberdade: a luta pelo reconhecimento da igualdade como direito à diferença no Discurso do Ódio. Brasília: Universidade de Brasília, 2009 [dissertação de Mestrado].

PRETES, Érika Aparecida, A criminalização do discurso de ódio homofóbico no Brasil Belo Horizonte, Faculdade de Direito da Universidade Federal de Minas Gerais, 2014 [dissertação de Mestrado].

PRETZEL, Bruna Romano, Argumentação sobre Liberdade de Expressão: 
Resultado da Análise de Votos do Min. Marco Aurélio, in Jurisprudência constitucional: como decide o STF?, org. COUTINHO, Diogo R; VOJVODIC, Adriana M., Malheiros, 2009, p. 53-67. São Paulo.

RAMOS, Patrícia Pimentel de Oliveira Chambers. Liberdade de expressão versus proteção de crianças e adolescentes. Revista da EMERJ. Rio de Janeiro. v.9. n.33. p.279-93. 2006.

REALE JÚNIOR, Miguel. Limites à liberdade de expressão. Revista Brasileira de Ciências Criminais. São Paulo. v.17. n.81. p.61-91. nov./dez. 2009.

REIS, Carine Delgado Caula, A dignidade da pessoa humana como limite ao exercício da liberdade de expressão, in Direito Civil Constitucional, org. LOTUFO, Renan, São Paulo, Malheiros, 2002.

RIOS, Aurélio Virgílio Veiga. Rádio comunitária: a liberdade de expressão e opinião e a restrição a seu exercício. Boletim dos Procuradores da República. São Paulo. v.4. n.47. p.3-11. mar. 2002.

RODRIGUES JR., Edson Beas, Solucionando o conflito entre o direito à imagem e a liberdade de expressão: a contribuição da jurisprudência da Corte Interamericana de Direitos Humanos, RT, v. 905, março 2011.

RODRIGUES, Marilene Talarico Martins, Liberdade de expressão e liberdade de informação: direitos fundamentais e democracia, in Princípios Constitucionais Relevantes - A constituição Interpretada pelo Conselho Superior da Fecomércio, Ives Gandra Martins (coord), 2011, Ed. Magister, Porto Alegre, 2012, p. 199. Disponível em http://www.multieditoras.com.br/produto/PDF/700140.pdf

RODRIGUES JUNIOR, Otávio Luiz, Justiça do Canadá amplia conceito de “discurso do ódio", disponível em http://www.conjur.com.br/2013-mai-01/direitocomparado-justica-canada-amplia-conceito-discurso-odio.

ROLLA, Giancarlo. El difícil equilibrio entre el derecho a la información y la tutela 
de la dignidad y la vida privada: breves consideraciones a la luz de la experiencia italiana. Cuestiones Constitucionales. México. n.7. p.139-67. jul./dic. 2002.

ROSENFELD, Michel. Hate speech in constitutional jurisprudende: a comparative analysis. Working Paper Series 41/11, 2001, p. 41. Disponível em: http://papers.ssrn.com/paper.taf?abstract_id=265939. Acesso em: 10.12.2012.

ROXIN, Claus. Tem futuro o direito penal?, in Revista dos Tribunais, São Paulo, n. 790, ago. 2001, p. 01-30.

SANTOS, Christiano Jorge. Crimes de preconceito e de discriminação, $2^{\mathrm{a}}$ ed., Saraiva, São Paulo, 2001.

SARMENTO, Daniel. A liberdade de expressão e o problema do hate speech. RDE: revista de direito do estado. Rio de Janeiro. v.1. n.4. p.53-105. out./dez. 2006.

SCHAFER, Gilberto, LEIVAS, Paulo Gilberto Cogo, HAMILTON DOS SANTOS, Rodrigo. Discurso de ódio: da abordagem conceitual ao discurso parlamentar, Revista de informação legislativa, v. 52, n. 207, p. 143-158, jul./set. 2015.

SCHAUER, Frederick. The boundaries of the first amendment: a preliminary exploration of constitutional salience. Harvard Law Review. Cambridge. v.117. n.6. p.1765-809. apr. 2004.

SÉRIE PENSANDO O DIREITO: o papel da vítima no processo penal, Brasília, Instituto Brasileiro de Ciências Criminais, nº 24, 2013.

SHECAIRA, Sérgio Salomão, Criminologia, 3ª edição, São Paulo, RT, 2011.

SILVA, Júlio César Casarin Barroso, Liberdade de Expressão e expressões de ódio. Revista Direito GV, v. 11, n. 1, p. 37-64, Jan/2015.

SILVA, Rosane Leal da, NICHEL, Andressa, MARTINS, Anna Clara Lehmann, BORCHARDT, Carlise Kolbe. Discursos de ódio em redes sociais: jurisprudência 
brasileira . Revista Direito GV. São Paulo. v.1. n.14. p.445-467. Dez/2011.

SILVEIRA, Renata Machado da. Liberdade de Expressão e discurso do ódio. Belo Horizonte: Pontifícia Universidade Católica de Minas Gerais, 2007 [dissertação de Mestrado].

SCHREIBER, Anderson, Direito e Mídia, Ed. Atlas, 1a edição, 2013.

SOBRADO DE FREITAS, Riva, DE CASTRO, Matheus Felipe. Liberdade de Expressão e Discurso do Ódio: um exame sobre as possíveis limitações à liberdade de expressão, Revista Sequência, v. 34, n. 66, p. 327-355, 2013.

SZKLAROWSKY, Leon Frejda. Crimes de racismo - crimes resultantes de discriminação ou preconceito de raça, cor, etnia, religião ou procedência nacional. Revista dos Tribunais. São Paulo. v.743. n.86. p.459-482. set/1997.

SWIEBEL, Joke; VEUR, Dennis Van Der. Hate crimes against lesbian, gay, bisexual and transgender persons and the policy response of international governmental organisations. Netherlands Quarterly of Human Rights. Cambridge. v.27. n.4. p.485524, Dec. 2009.

TASSINARI, Clarissa; JACOB DE MENEZES NETO, Elias. Liberdade de expressão e Hate Speeches: as influências da jurisprudência dos valores e as consequências da ponderação de princípios no julgamento do caso Ellwanger, Revista Brasileira de Direito, v. 9, n. 2, p. 7-37, jan/2014.

TASSOPOULOS, Ioannis A. Hate speech and liberal democracy. Perspectives from Greece. Revue Hellénique de Droit International. Athenas. v.55. n.1. p.241-58. 2002.

TRAGER, Robert; CHAMBERLIN, Bill F. The dangerous exception to protection for opinion. Communications and the Law. Westport. v.11. n.4. p.51-64. dec. 1989.

VECCHIATTI, Paulo Roberto Iotti, Constitucionalidade da classificação da homofobia como racismo (PLC 122/2006), in Diversidade Sexual e Direito 
Homoafetivo, coord. DIAS, Maria Berenice, RT, 2011.

VIENA VIEIRA, Oscar, Direitos Fundamentais, uma leitura da jurisprudência do STF, colab. Flávia Scabin, Ed. Malheiros, São Paulo, 2006. 